\title{
Health Hot Spots: Mapping Hospital Costs and Social Determinants of Health
}

\author{
Jessica Holzer1,2, Maureen Canavan1, Emily Cherlin1,3, Elizabeth Bradley1,3 \\ ${ }^{1}$ Department of Health Policy and Management, Yale School of Public Health, New Haven, Connecticut, USA \\ ${ }^{2}$ Department of Health Professions, Hofstra School of Health Sciences and Human Services, Hempstead, NY, \\ USA \\ ${ }^{3}$ Global Health Leadership Institute, Yale University, New Haven, Connecticut, USA \\ Email: jessica.k.holzer@hofstra.edu
}

Received 4 August 2014; revised 5 September 2014; accepted 21 September 2014

Copyright (C) 2014 by authors and Scientific Research Publishing Inc.

This work is licensed under the Creative Commons Attribution International License (CC BY).

http://creativecommons.org/licenses/by/4.0/

\begin{abstract}
Accountable care organizations (ACOs) and hospitals are facing additional requirements and financial rewards for improving population health. Therefore, ACOs and hospitals will need tools to understand the relationship between their patients and social determinants and health. We demonstrate the use of hot spotting for identifying geographical sources of high hospital costs and examining links between social determinants of health and these high-cost areas, known as hot spots. In 2012, using hospital data, we generated maps of inpatient costs from 2011 throughout New Haven and within an example neighborhood, Dixwell. We defined hot spots as addresses where costs were in the top $25 \%$. We also overlaid data on concerns and assets in the community. Finally, we calculated the number of concerns and assets that fall within the 250 and $500 \mathrm{ft}$ radii of the defined hot spots. We found that 34 addresses in Dixwell accounted for $\mathbf{7 0 \%}$ of total costs for Dixwell. Hot spotting is a straightforward, approachable, and easily understood method for ACOs and hospitals to begin to address population health.
\end{abstract}

\section{Keywords}

Mapping, Healthcare Costs, Social Determinants of Health, Health Disparities, Hot Spots

\section{Introduction}

Healthcare costs in the United States continue to increase faster than the economy [1], creating a demand for creative solutions to cost containment. Part of the proposed solution has been to make hospitals and accountable care organizations (ACOs) more responsible for prevention, overall population health, and cost containment. 
This shift from a patient-centered focus to a population- and community-based focus will require hospitals to think of their populations more broadly [2]. More importantly, hospitals and ACOs will need to think about social and economic determinants of health for the population. With new goals of improving population-based health outcomes, hospitals will benefit from tools that identify social and economic determinants of health affecting their patients and healthcare spending. Data from such tools can guide hospital priority-setting and program design to serve their population.

A novel tool called hot spotting has been described in the grey literature [3] and has been used largely to identify and target patients with extremely high emergency room utilization. "Hot spotting" is the term used for the process of identifying geographic locations where health or safety concerns concentrate [3]. For instance, in Camden, New Jersey, a physician and his team identified where emergency department "super-utilizers" lived and provided improved case management and primary care to prevent emergency room visits. Similarly, geocoding efforts in public health research have linked health concerns such as asthma and lead poisoning to socioeconomic factors that are geographically associated with their diseases [4] [5]. In this research, Krieger and colleagues concluded that socioeconomic factors in the communities where patients live are predictive of patient re-hospitalization, demonstrating the importance of understanding community-level factors that affect hospital utilization.

Despite its relevance to public health [3], applications of hot spotting in public health have not been described in peer-reviewed literature, nor has hot spotting been used as broadly as may be valuable. To our knowledge, hot spotting has not been employed to identify community characteristics that might associate with healthcare cost hot spots. Accordingly, we sought to demonstrate the use of hot spotting in a pilot project for identifying geographical sources of high hospital costs and examine associations between selected social and economic determinants (e.g., housing, crime, and neighborhood assets) and these high-cost areas, known as hot spots. Using hospital inpatient admissions data, we mapped health care costs by address, as well as data on housing quality, crime, and availability of health care providers and other community assets in a neighborhood of New Haven, Connecticut. Below, we describe our methods in brief and then discuss the results, which we believe demonstrate how relatively simple mapping of health care costs and socioeconomic determinants of health can be used to visualize relationships between individuals and aggregated health care costs and the determinants known to affect health and well-being of populations.

\section{Methods}

The city of New Haven has nearly 130,000 residents and is the second largest city in Connecticut [6]. In 2010, the most recent year for which data are available, the median age of residents in New Haven was 29.9 years and approximately 35\% of residents identified as black or African American [6]. At the time of data collection, Yale-New Haven Hospital (YNHH) was the largest hospital in Connecticut. In 2011, YNHH had more than 700,000 outpatient and emergency department (ED) visits and approximately 57,000 inpatient discharges [7].

We piloted this project and focused the community-level data collection efforts in a single neighborhood known as Dixwell, which we chose because it is proximate to YNHH and concern and asset data were available for it as well. Dixwell has a geographic area of 0.46 square miles and is located within 2 miles of YNHH. Nearly $25 \%$ of its residents are under the age of 18 and approximately $75 \%$ of residents identify as black or African American. Only $40 \%$ of Dixwell's population is participating in the labor force, of which $5 \%$ are unemployed. More than 25\% of residents are living below the poverty line [8].

We conducted a cross-sectional analysis of hospital admissions data from YNHH for all patients in New Haven under age 65 who were both admitted and discharged in 2011. Only patients whose addresses were within New Haven were included in the analysis. We limited the data to persons under the age of 65 because costs for the elderly are known to be higher on average than those for the non-elderly [9] and therefore would mask geographic variations in costs for those under 65 . We also obtained cross-sectional community-level data from publicly available records, walking assessments, and resources provided by the New Haven Police Department. All research procedures were approved by the Institutional Review Board of Yale School of Medicine and all research was conducted to protect the privacy of patient records.

We characterized community-level data as concerns and assets. Concerns included violent crime locations, foreclosures, low-property quality ratings, and alcohol retailers. The New Haven Police Department provided data on the locations and types of violent crimes (e.g., homicides, rape, aggravated assault and armed robbery). 
Assets were ascertained using a community capacity inventory adapted from the Community Tool Box [10] during walking tours throughout the Dixwell neighborhood in 2012. Researchers recorded the addresses of community centers, churches, domestic violence shelters, food kitchens, emergency housing shelters, schools, city and state agencies, municipal libraries, parks, medical services, including medical centers and doctors' offices, emergency services (e.g., fire and police stations), and businesses, all of which were considered assets.

We geocoded the YNHH and community data and created a heat density map, which plots a color distribution from green to red based on the total annual expenditure for that area, showing the distribution in expenditures across all New Haven neighborhoods. The resulting map showed areas that had the highest total expenditure (in dollars) in red and areas with the lowest total expenditure in green.

We isolated hospital data for Dixwell and overlaid concern and asset data onto two separate heat maps of the Dixwell neighborhood. Using ArcGIS spatial analysis tool we identified the number of each type of concern and asset as well as the overall number of concerns and assets respectively located within a 250 or 500 foot radius of a hot spot. Then we calculated the percentage of each type of concern and asset within 250 and 500 feet of a hot spot by dividing the number of each concern and asset within a 250 or 500 foot radius of a hot spot by the total number of that type of concern or asset located within the entire Dixwell neighborhood. All analyses were performed using Arc GIS version 10 and SAS version 9.2.

\section{Results}

A total of 7628 patients younger than 65 years accounted for 11,056 hospital admissions for a total cost of more than \$125 million in New Haven in 2011. Of addresses in New Haven that were sources of hospital expenditures, the least expensive was $\$ 1852$ and the most expensive was $\$ 413,918$ with the distribution of expenditures varying throughout the city (Figure 1).

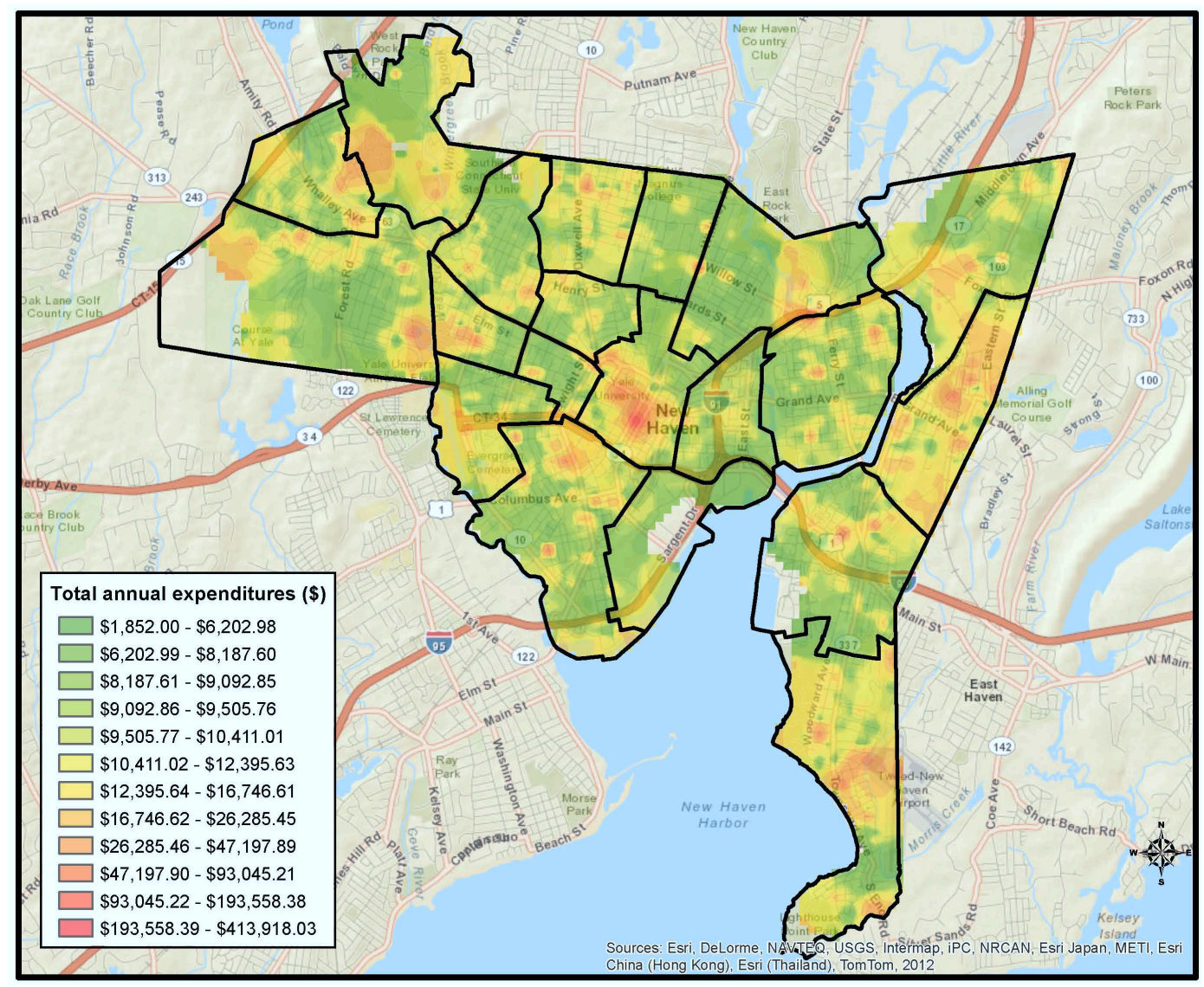

Figure 1. Yale-New Haven Hospital 2011 total inpatient expenditures for individuals younger than 65 years in New Haven City. 
Within Dixwell, 34 addresses were in the top quartile of expenditures per address and together accounted for nearly $70 \%$ of total hospital expenditures incurred by Dixwell residents in 2011. Each of the 34 addresses generated an annual total inpatient expenditure of more than $\$ 18,400$.

Comparing the concerns (i.e., violent crime locations, foreclosures, low-property quality ratings, and alcohol retailers) and hot spots, we found that more than three-quarters (78\%) of poor-quality properties and $78 \%$ of violent crimes were located within 500 feet of a hot spot; more than $43 \%$ of these were located within 250 feet of a hot spot (Figure 2).

In terms of assets in Dixwell, we identified 1 housing organization, 1 library, 1 federally qualified health center, 1 eye doctor, 3 community centers (two senior centers and one youth-reading-focused center), 3 schools, and 18 churches. We identified no dentists, psychiatric professionals, social workers, or other allied medical service providers within the community. Overall, only 19\% of assets were located within 250 feet of a hot spot; 69\% were located within 500 feet of a hot spot (Figure 3).

\section{Discussion}

We found that nearly $70 \%$ of all hospital expenditures in 2011 for the neighborhood of Dixwell were attributed to people living at 34 addresses. Additionally, almost half of the poor housing and violent crimes but less than $20 \%$ of assets were located within 250 feet of these 34 addresses. Using our method, we were able to visually demonstrate potentially interesting relationships between health care costs and community characteristics.

The method should be employed in light of several limitations. We do not know the significance of the proximity of concerns or assets to hot spots without further study, and the significance may vary for individual cities

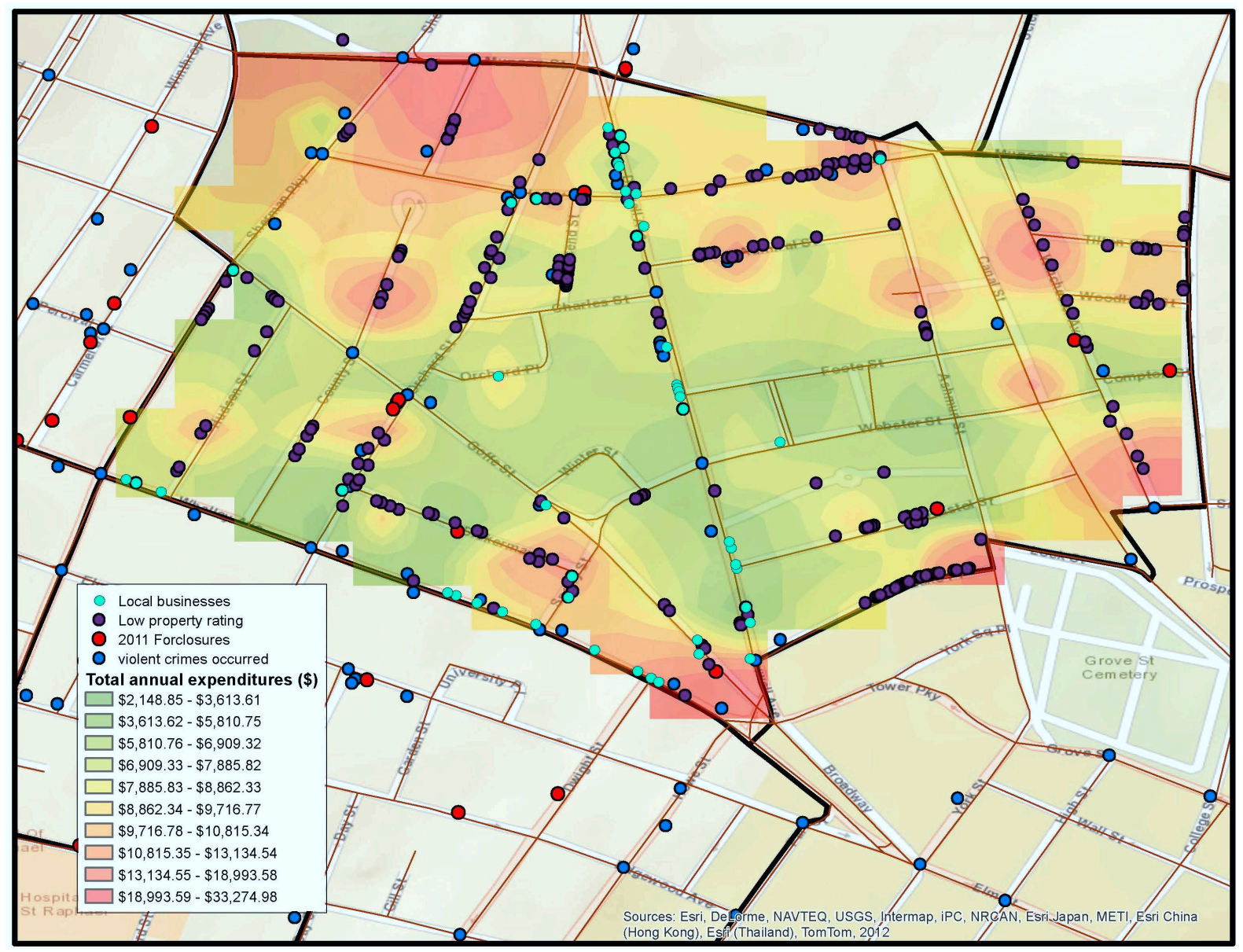

Figure 2. Yale-New Haven Hospital total expenditure hot spots and neighborhood concerns for individuals younger than 65 years in Dixwell neighborhood. 


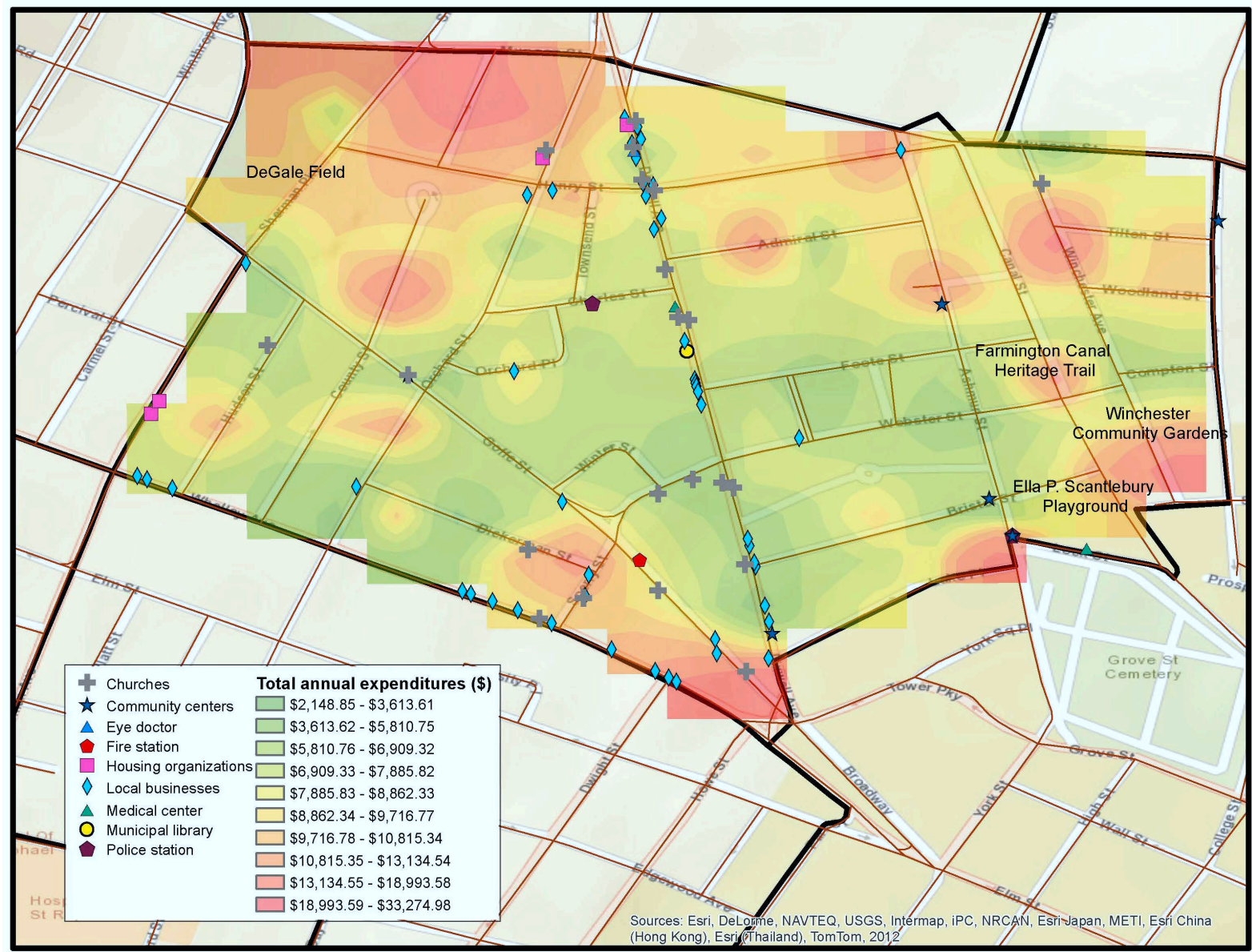

Figure 3. Yale-New Haven Hospital total expenditure hot spots and neighborhood assets for individuals younger than 65 years in Dixwell neighborhood.

or neighborhoods depending on local characteristics. Furthermore, the nature of the data will strongly determine the value of the findings in the mapping process, and hospitals or providers who have incomplete addresses for many of their patients or incomplete expenditure data may not find the hot spotting method useful.

The hot spotting method can help stakeholders who are responsible for their community's health and health care costs identify relationships between spending and socioeconomic determinants that may be relevant. Currently, hospitals spend an average of $7.5 \%$ of all operating expenses on community benefit programs. The majority of this is for providing charity care for patients who are indigent with less than $1 \%$ invested directly in community prevention and health improvement efforts [11]. If stakeholders, including hospitals and ACOs, were to employ this hot spotting method in their own communities, using their cost data, hospitals may better target their investments in community health, potentially increasing return-on-investment, reducing high hospital expenditures, and improving overall community health.

\section{References}

[1] Kaiser Family Foundation (2012) Costs. JAMA, 308, 1197-1197. http://dx.doi.org/10.1001/2012.jama.11916

[2] Kindig, D. and Stoddart, G. (2003) What Is Population Health? American Journal of Public Health, 93, 380-383. http://dx.doi.org/10.2105/AJPH.93.3.380

[3] Gawande, A. (2011) The Hot Spotters. The New Yorker, Conde Nast, New York.

[4] Beck, A.F., Simmons, J.M., Huang, B. and Kahn, R.S. (2012) Geomedicine: Area-Based Socioeconomic Measures for Assessing Risk of Hospital Reutilization among Children Admitted for Asthma. American Journal of Public Health, 102, 2308-2314.

[5] Krieger, N., Chen, J.T., Waterman, P.D., et al. (2003) Choosing Area Based Socioeconomic Measures to Monitor So- 
cial Inequalities in Low Birth Weight and Childhood Lead Poisoning: The Public Health Disparities Geocoding Project (US). Journal of Epidemiology Community Health, 57, 186-199. http://dx.doi.org/10.1136/jech.57.3.186

[6] State \& County QuickFacts (2010) New Haven, Connecticut. Cited 2013 Sept 3. http://quickfacts.census.gov/qfd/states/09/0952000.html.

[7] (2013) About Yale-New Haven Hospital. Cited 2013 Sept 3. http://www.ynhh.org/about-us/default.aspx.

[8] (2005) DataHaven Neighborhood Profile: Dixwell. Cited 2013 Sept 3.

http://www.ctdatahaven.org/reports/neighborhoodProfiles/Dixwell_CensusNP.pdf

[9] Stanton, M.W. (2014) The High Concentration of U.S. Health Care Expenditures: Research in Action. Issue 19, June 2006, Agency for Healthcare Research and Quality, Rockville, MD.

http://www.ahrq.gov/research/findings/factsheets/costs/expriach/index.html

[10] Berkowitz, B. and Wadud. E. (2013) Identifying Community Assets and Resources. The Community Tool Box. http://ctb.ku.edu/en/tablecontents/sub_section_tools_1043.aspx.

[11] Young, G.J., Chou, C.-H., Alexander, J., Lee, S.-Y.D. and Raver, E. (2013) Provision of Community Benefits by Tax-Exempt U.S. Hospitals. New England Journal of Medicine, 368, 1519-1527. http://dx.doi.org/10.1056/NEJMsa1210239. 
Scientific Research Publishing (SCIRP) is one of the largest Open Access journal publishers. It is currently publishing more than 200 open access, online, peer-reviewed journals covering a wide range of academic disciplines. SCIRP serves the worldwide academic communities and contributes to the progress and application of science with its publication.

Other selected journals from SCIRP are listed as below. Submit your manuscript to us via either submit@scirp.org or Online Submission Portal.
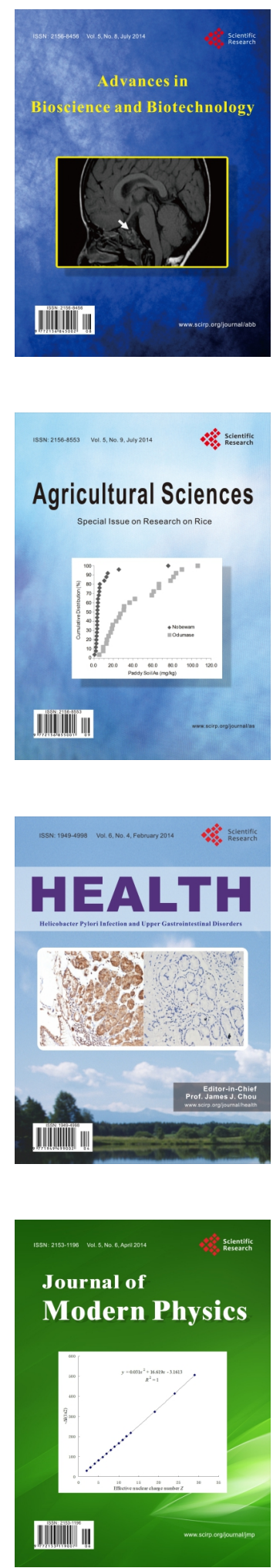
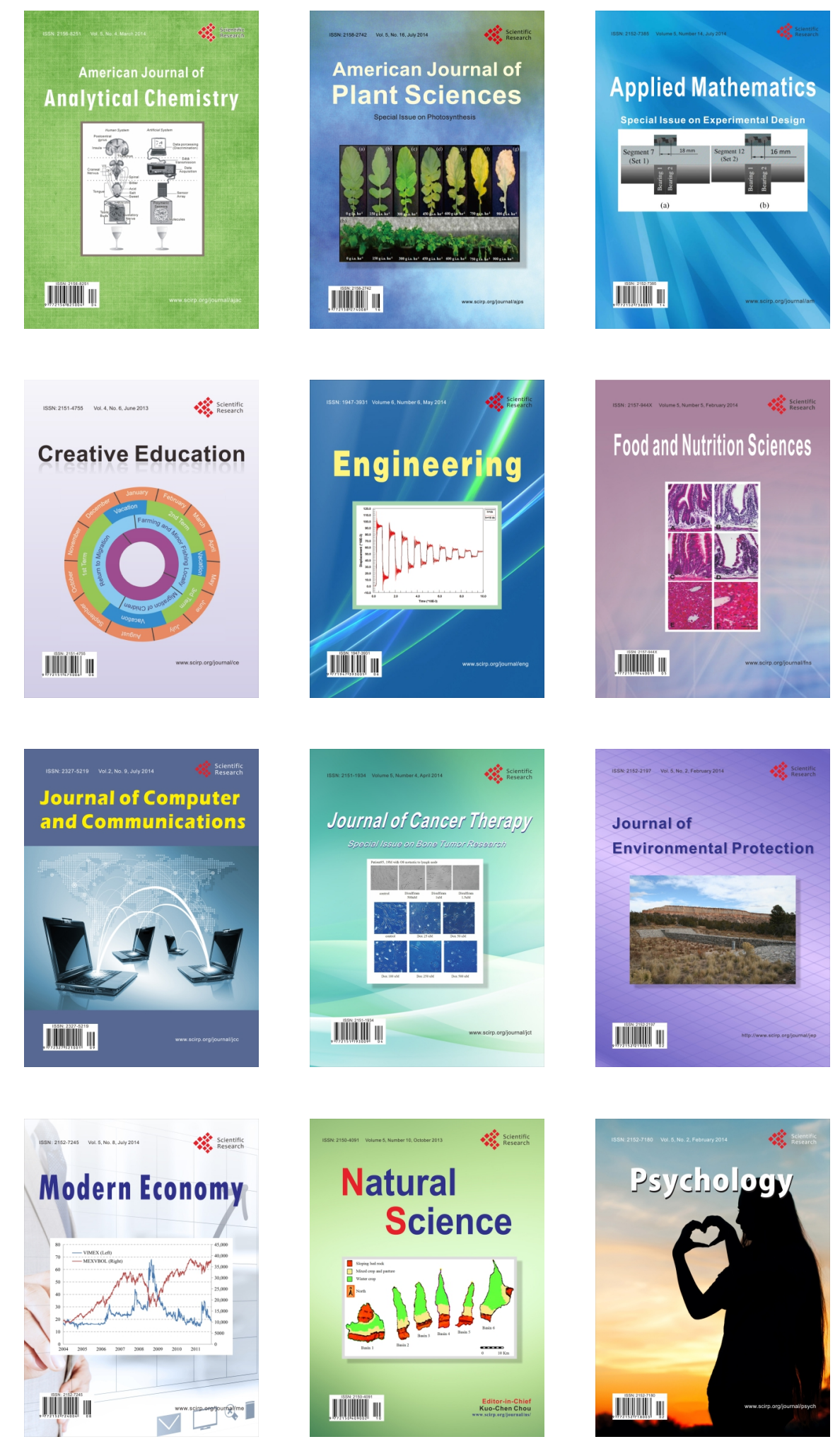